\title{
THE PLACENTA IN HEMATOGENOUS INFECTIONS
}

\author{
Achiléa Lisboa Bittencourt $\square$ Department of Pathology, \\ Federal University of Bahia, Brazil
}

Aparecida Gomes Pinto Garcia $\square \quad$ Laboratory of Pathology, Instituto Fernandes

Figueira, Oswaldo Cruz Foundation, Rio de Janeiro, Brazil (in memoriam)

Although congenital infections have been known since ancient times, at present they constitute an evolution due to the broadening of diagnostic metho00ds. Also, the histopathological examination of selected placentas has increased in perinatal pathology. All placentas should be examined grossly by the obstetrician or the neonatologist who must select the specimens to be sent for pathologic examination. The indications for selection at delivery to detect hematogenous infection are listed in Table 1. The placentas that do not meet guidelines for pathologic examination must be kept stored at $4^{\circ} \mathrm{C}$ for at least $72 \mathrm{~h}$. This routine ensures that the placentas of asymptomatic newborns who might present early manifestations suggestive of infection would be submitted for pathologic examination.

\section{MACROSCOPIC EXAMINATION}

The placentas associated with perinatal deaths usually exhibit an increase in weight and size as well as other features. In these cases the lesions are diffuse and severe, and they involve predominantly the villous plate. Hypotransparency of the fetal surface and thickening of the chorionic vessels are observed (Figure 1). The maternal surface is pale and friable and presents an edematous aspect (Figure 2). In cases of fetal hydrops the placenta is also hydropic. Nevertheless, the gross placental aspect may be apparently normal when associated with asymptomatic or mild symptomatic babies. In contrast to ascending infections, the free placental membranes generally preserve their transparency in hematogenous infections. Meconium impregnation of the membranes and umbilical cord are frequently observed in these placentas, indicating subacute or chronic fetal distress [1].

The umbilical cord must be examined macroscopically in all its length because the distribution of the lesions are random. In cases of more severe infection, Wharton jelly may exhibit diffuse opacity or pearly areas intermingled with apparently normal areas. Segmental thickening, thrombosis, necrosis, and/or calcification of the umbilical vessels (Figure 3) also may be observed [1].

Address correspondence to Achiléa L. Bittencourt, MD, Hospital Prof. Edgard Santos, Serviço de Anatomia Patológica, Rua Augusto Viana s/n - Canela CEP: 40110-160, Salvador-Bihia-Brasi 1. E-mail: achilea@ uol.com.br 
TABLE 1. Indications for Placental Histopathologic Examination for Detection of Hematogenous Infection [99]

Diagnosis or suspicion of maternal infection

Pregnant women from a highly endemic area for placentally transmissible infections

History of previous stillbirths and/or neonatal deaths

Conceptuses small-for-date or prematures weighing less than $2000 \mathrm{~g}$

Fetal ultrasound abnormalities suggestive of congenital infection

Congenital infection diagnosed by cordocentesis or amniocentesis

Ultrasonographic or gross placental abnormalities suggestive of hematogenous infection

Fetal distress of unknown cause

Clinical manifestations of the newborn suggestive of infection within the first $72 \mathrm{~h}$ of life

Stillbirths or neonatal deaths

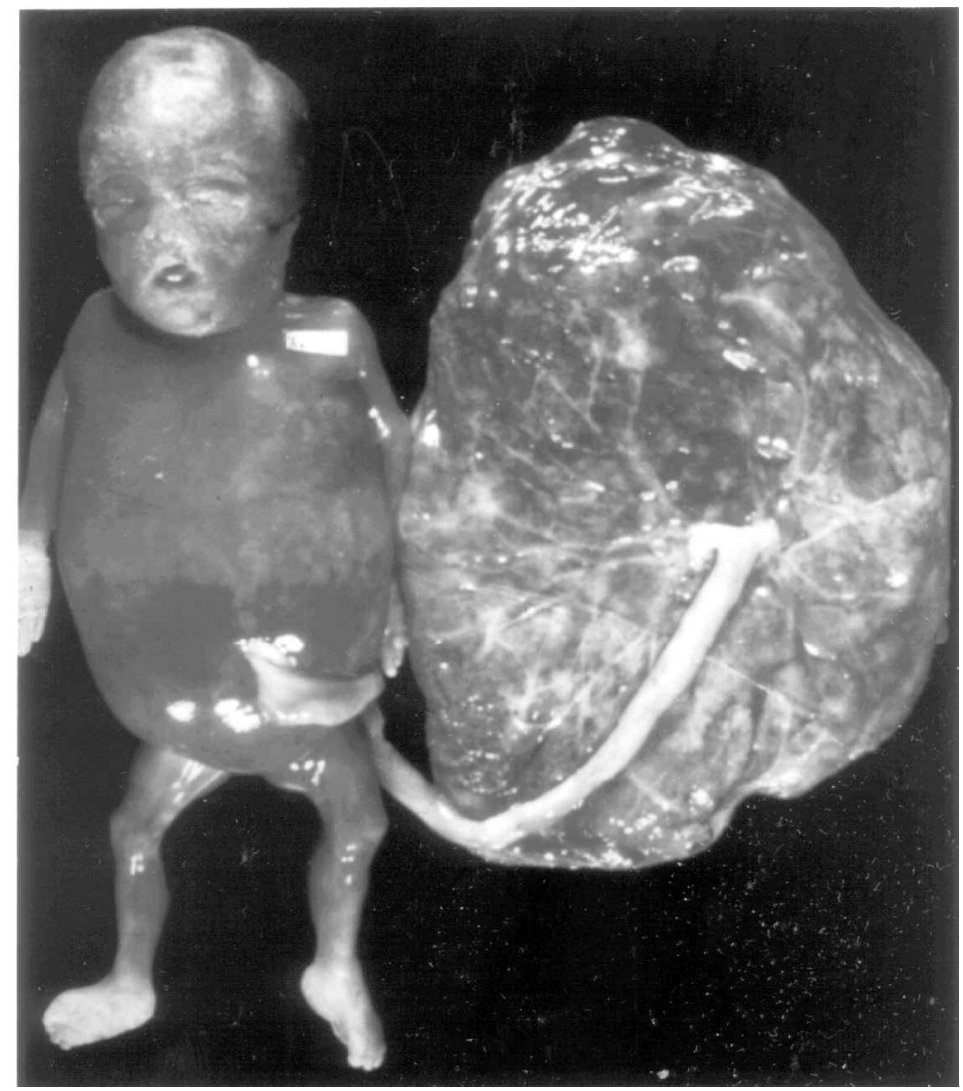

FIGURE 1. Parvovirosis (confirmed by in situ hybridization). Fetoplacental hydrops. There is partial lack of transparency of the placental fetal surface. 


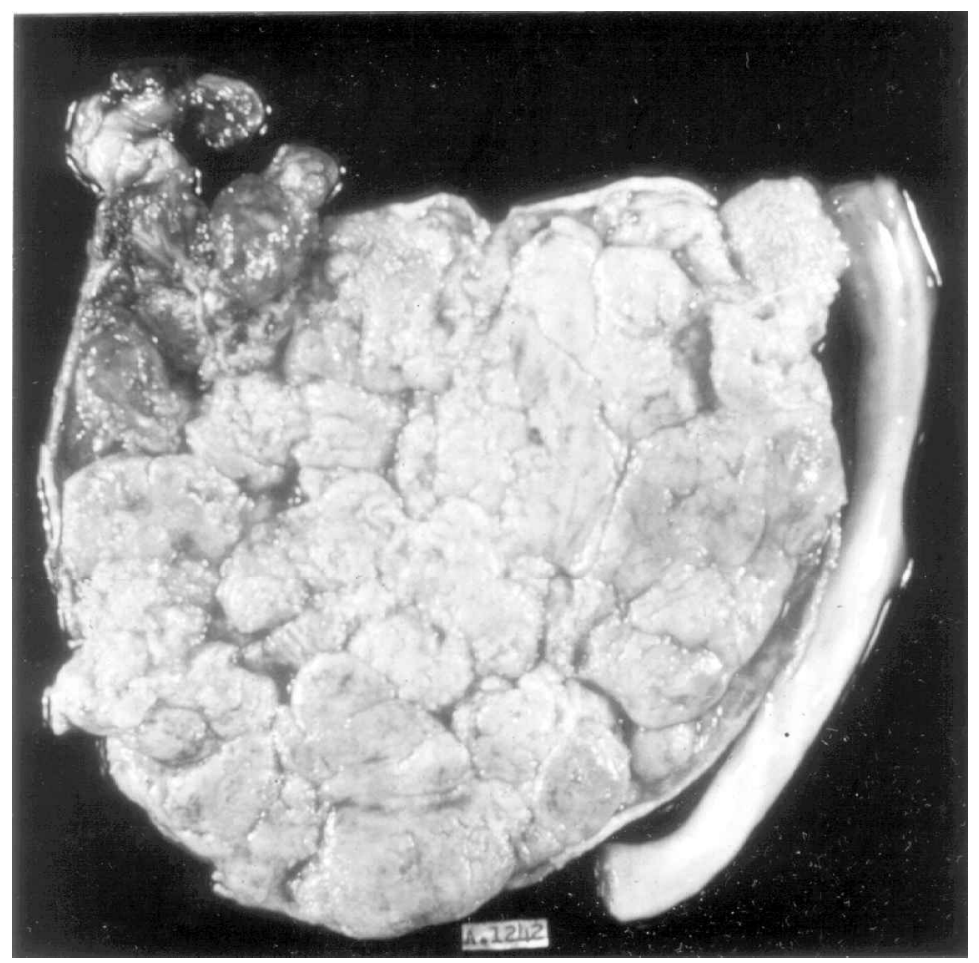

FIGURE 2. Chagasic placentitis. The placental lobules are pale and bulky.

The best fixative for the placenta is buffered formalin. For studies with immunocytochemistry and molecular biology fixation time must be very short. For microscopic study four sections including both plates must be made in each quadrant avoiding the marginal areas. Sections of both ends of the umbilical cord and of the roll of the free placental membranes also must be included.

\section{MICROSCOPIC EXAMINATION}

Villitis frequently represents an indication of maternal bloodborne infection. When associated with asymptomatic or mild symptomatic neonates, it is usually focal and mild. On the other hand, diffuse villitis is generally associated with stillbirths or neonatal deaths. Villitis may be chronic, chronic granulomatous, subacute, or acute. When present in the anchoring villi it is referred to as basal villitis. Villitis is generally associated with collections of inflammatory maternal cells in the surrounding intervillous space (intervillitis) predominantly in areas of trophoblastic necrosis [1].

Villitis has been classified as proliferative, necrotizing, reparative, and fibrotic. The proliferative type is represented by inflammation without necrosis. An association of inflammation and necrosis characterizes the necrotizing type. In reparative 


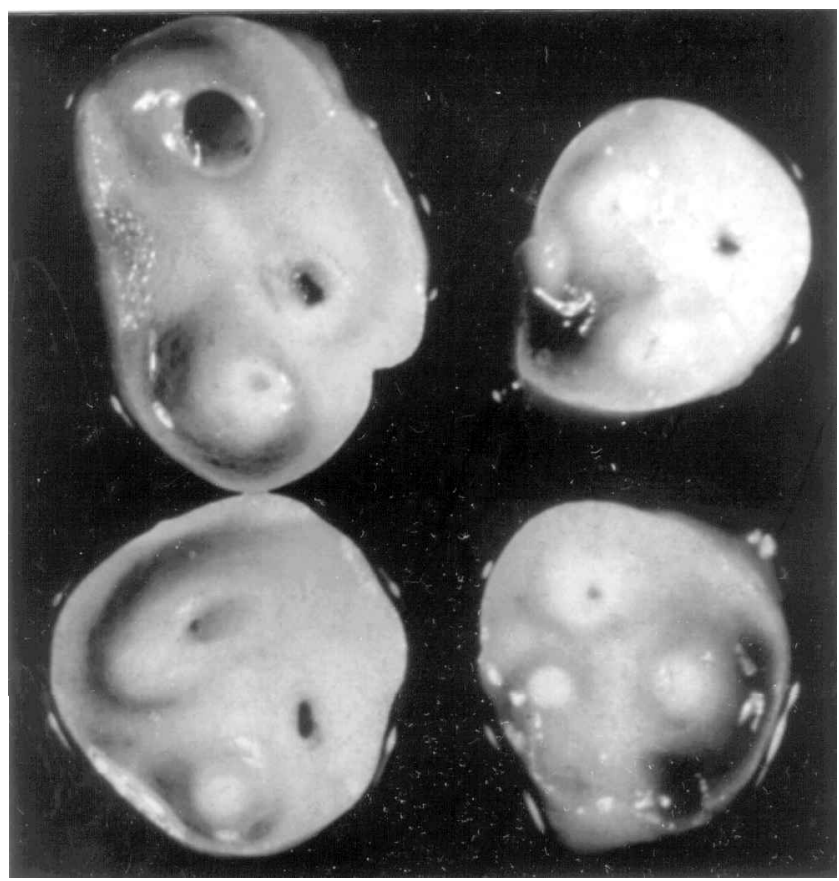

FIGURE 3. Necrotising funisitis (syphilis). See milk areas corresponding to necrosis of the umbilical vessels.

villitis, there are cicatricial changes, vascular obliteration, and evanescent villitis. The villi are scarred and shrunken with no inflammatory cells in fibrotic villitis [2]. These types of villitis may be observed simultaneously as a consequence of the prolonged action of microorganisms during the course of the pregnancy.

The great majority of villitis are of unknown etiology. The frequency of villitis of unknown etiology (VUE) varies from 6 to $26 \%$ in international series [3]. VUE constitutes an important cause of intrauterine growth retardation (IUGR) and recurrent reproductive failure. Garcia studying 50 placentas of small-for-gestational age (SGA) babies of low-income women, found hematogenous placentitis in $74 \%$ of the specimens, most of them VUE [4]. There are no morphologic differences between the substantial majority of specific villitis and VUE $[3,5]$.

VUE has been explained by two theories. One proposes that this lesion represents a fetal immune response to microbial antigen, whereas the other suggests that maternal cells invade the maternofetal barrier and mount an immune response to fetal antigens [6]. The phenotype of the inflammatory cells in VUE consists of macrophages and T-lymphocytes with predominance of the latter cells [6, 7]. In VUE placentas 30 to $54 \%$ of the inflammatory cells are of maternal origin. However, the presence of maternal lymphocytes within the villi does not exclude an infectious etiology for this lesion [6]. Moreover, in the presence of villitis unrecognized infections cannot be excluded, mainly in developing countries where the 
frequency of congenital infections is much higher than in industrialized countries [1].

Chronic intervillositis without villitis in nonmalaria women constitutes a condition associated with poor fetal outcome. It is composed mainly of macrophages. Its association with increased villous fibrinoid material and atherosis suggest an immunologic origin, although the possibility that this lesion may have an infectious cause cannot be excluded [8]. Other aspects observed in hematogenous placentitis include:

1. Abnormalities in early placental development observed in some viral infections. The early localization of the viruses in the endothelium arrests the normal development of the vessels and impairs the sinusoidal transformation of the chorionic villous capillaries.

2. Involvement of the capillary bed represented by focal endothelial necrosis, pycnosis, and karyorhexis (Figure 4).

3. Delay in the maturation process.

4. Subchorionic intervillitis and chorioamnionitis.

5. Fetal nucleated red blood cells in the villous vessels mimicking fetal erytroblastosis [1,3,9-11].

In the umbilical cord, there is inflammatory infiltration in or around the vessel walls, sometimes associated with necrosis and calcification (necrotizing funisitis) [1].

The placental histologic features are similar in several hematogenous placentitis. Thus, it is very important to detect the etiologic agent. However, through routine microscopic examination, the etiologic agent is not detected in most placentas. Notwithstanding, this routine examination always indicates the type of

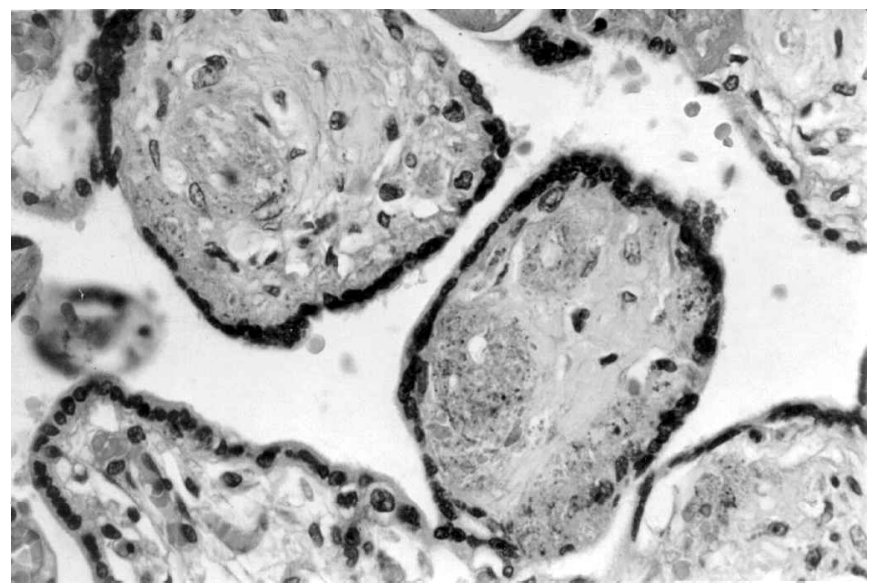

FIGURE 4. GMV infection. The villi vessels show necrosis and karyorhexis $(\mathrm{H} \& \mathrm{E}, \times 250)$. 
congenital infection, either hematogenous or ascending, giving the neonatologist a direction to search for the etiology of infection in the mother and/or the newborn. The hematoxylin-eosin $(\mathrm{H} \& \mathrm{E})$ routine staining in some cases must be complemented by such other stainings as the periodic acid Schiff (PAS), Shorr, Brown-Hopps (a modified Gram stain), Warthin-Starry, etc. Immunohistochemical methods using monoclonal antibodies in fresh or paraffin-embedded tissue sections enhance the etiologic diagnosis.

There are other methods to detect the etiologic agent: culture and animal inoculation of placental tissues, electron microscopy, and molecular biology techniques using formalin-fixed paraffin-embedded tissues. The best method of molecular biology to visualize microorganisms in the placenta is in situ hybridization of nucleic acids. It identifies the localization of the agent, making it possible to document its passage through the trophoblastic epithelium. Polymerase chain reaction (PCR) is a very sensitive method and may also be performed on paraffin-embedded tissues. As it does not localize the microorganism, PCR is not the diagnostic tool of choice for placental infections. Some of these laboratory techniques are expensive and only available in reference centers and for few microbes [1].

It is important to emphasize the value of associating maternal data and clinicolaboratory aspects of the newborn with the pathologic placental findings to have more successful results in the etiologic diagnosis of the infections. In cases of perinatal deaths, it is necessary to correlate the autopsy findings with the pathologic examination of the placenta [1].

\section{RUBELLA}

Macroscopic findings are not seen in a great number of infected placentas. Small placentas may be observed. The chorionic plate may exhibit segmental areas of hypotransparency, usually perivascular. In addition, the chorionic vessels may appear prominent due to thickening of their walls. The umbilical cord may present whitish opaque zones and thickening of its vessels [10].

The placenta and the umbilical cord show generalized vasculitis with endothelial necrosis and karyorhexis due to the endothelial fixation of rubella virus. Acute villitis and intervillitis associated with trophoblastic necrosis and stromal hypercellularity also are observed (Figure 5). Dysmaturity of the stem villi and terminal villi constitute a prominent aspect due to inhibition of mitosis and consequently impairment of structural differentiation. In the basal and capsular decidua, a mononuclear infiltration is usually seen. Round or ovoid intranuclear or intracytoplasmic eosinophilic inclusions delineated by a clear halo may be seen in H\&E stained sections (Figure 6). They are also PAS positive, and stain red by the Shorr method. The inclusions are more frequently seen in decidual cells, extravillous cytotrophoblast, vascular endothelium, and amniotic epithelium. The rubella virus has been isolated from the placenta, and the viral antigen has been identified in the placentas and adnexae through the indirect immunofluorescent test [10]. 


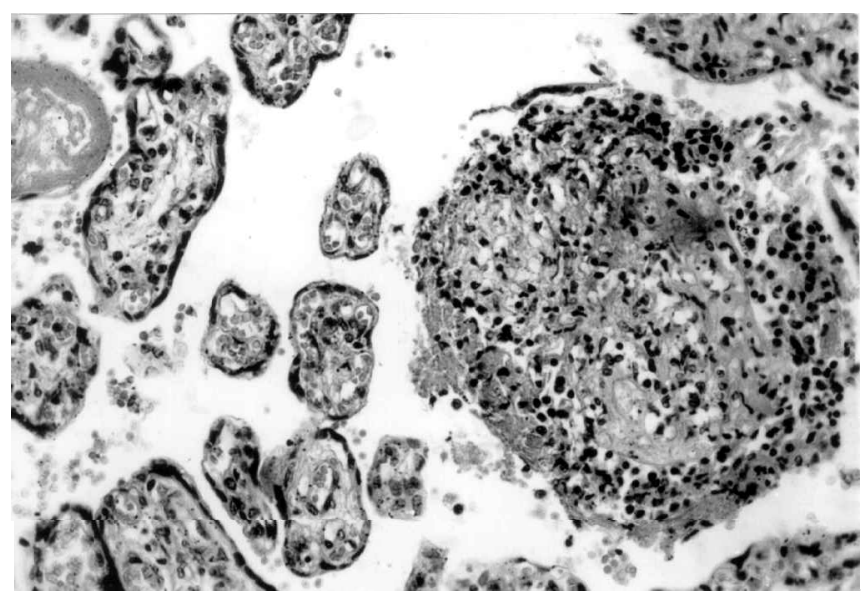

FIGURE 5. Rubella infection. At right see confluent villi with acute vasculitis and necrosis of the trophoblast. Around them are an infiltration of neutrophils in karyorhexis and mononuclear cells. (H\&E, $\times 200)$.

\section{CYTOMEGALOVIRUS INFECTION}

Cytomegalovirus (GMV) infection constitutes a major cause of chronic villitis. Placental hypoplasia associated with SGA babies as well as thrombosis of the chorionic vessels and focal thickening of the membranes have been observed [12, 13]:

The microscopic features are often so scarce that only careful examination of many sections may detect the lesions. Vascular necrosis (Figure 4), lymphoplasmacytic infiltration, villous necrosis, and fibrosis are the main features of CMV placentitis and they may appear simultaneously. A granulomatous placentitis, villous immaturity, and increased number of macrophages can also be seen. The chorionic vessels may present inflammation sometimes associated with thrombosis. When

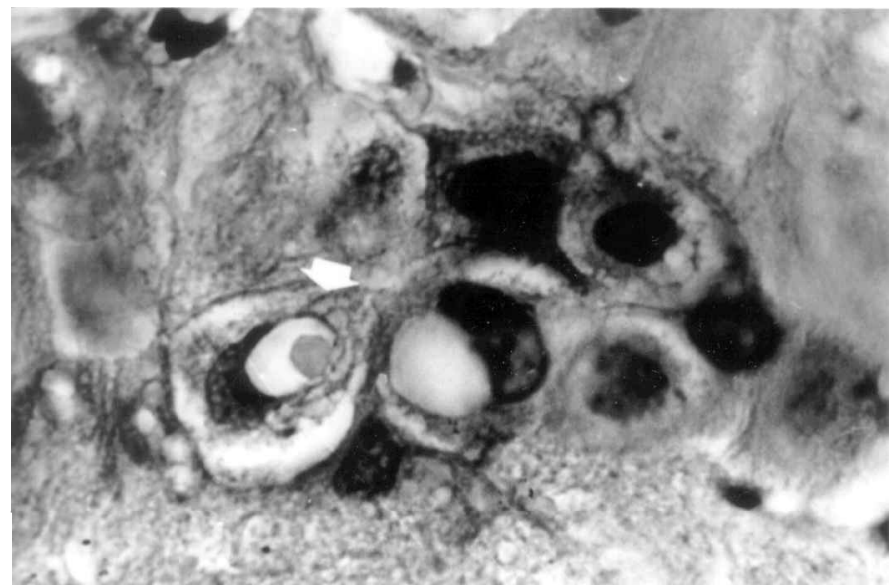

FIGURE 6. Rubella. Note an intranuclear inclusion in a decidual cell $(\mathrm{H} \& \mathrm{E}, \times 1200)$. 


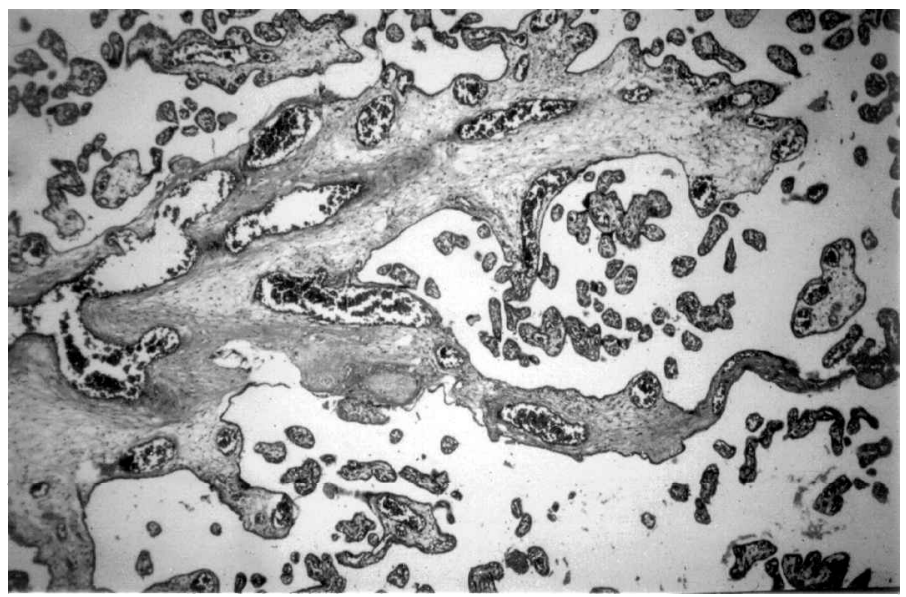

FIGURE 7. GMV infection. There is placental dismaturity and the stem villus and the chorionic villi appear atrophic and malformed $(\mathrm{H} \& \mathrm{E}, \times 40)$.

infection occurs early during gestation, a disordered development takes place and the stem villi as well as the chorionic villi may appear atrophic and malformed (Figure 7). Necrotizing villitis has been observed in term placentas and constitutes evidence of recent infection [12].

An aspect suggestive of CMV infection is the deposition of hemosiderin pigment around and within the villous vessels $[3,5]$. However, the presence of iron deposits along the trophoblastic basement membrane and within Hofbauer cells must not be interpreted as evidence of infection because they can be seen in normal placentas [14].

Phenotyping characterization of the inflammatory infiltration of CMV placentitis demonstrates plasma cells, T-lymphocytes, and macrophages [5, 15]. However, plasma cells may be absent in CMV placentitis [15].

The presence of typical cytomegalic cells with "owl-eye" inclusion (Figure 8) confers the diagnosis. However, they are more frequently found in placentas of abortions [12]. The inclusions are generally seen in the villous capillary endothelium but they also can be found in the stromal cells, trophoblast, decidua, and amnion $[12,16]$. The cytomegalic cells are not always typical, probably caused by early necrosis and mineralization. Infected cells also may present intracytoplasmatic inclusions, but they are not diagnostic. In cases of doubt, methods of immunohistochemistry or in situ hybridization can clarify the diagnosis [17-20]. These methods enable the diagnosis even when there is no evidence of placentitis [20].

\section{HUMAN IMMUNODEFICIENCY VIRUS (HIV) INFECTION}

Placental infection by HIV may occur as early as the eighth week of gestation [21]. No gross abnormalities have been observed in these placentas. Microscopically 


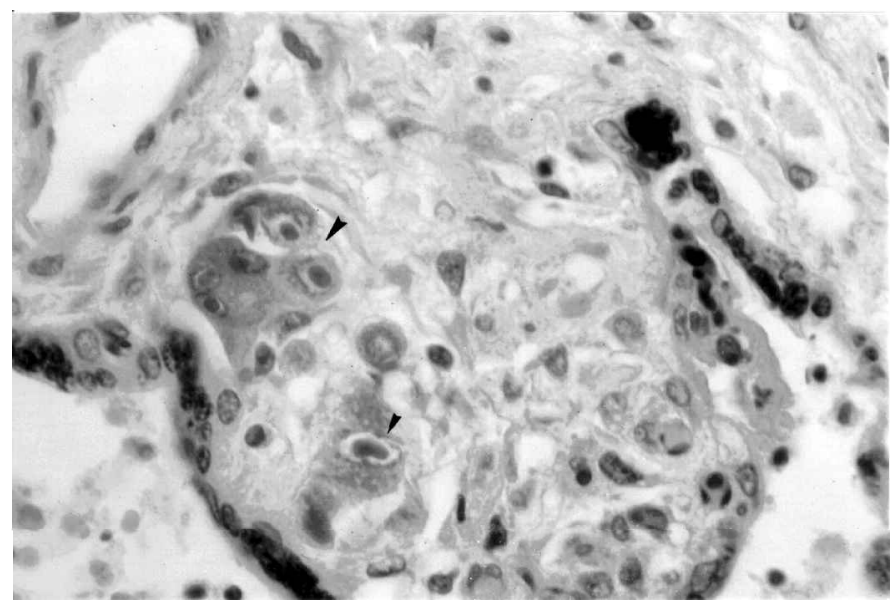

FIGURE 8. CMV. Typical cytomegalic cells with "owl-eye" inclusions (arrows) in a villus (H\&E, $\times 800)$.

villous hypercellularity, immaturity of the terminal villi, and vasculopathy have been described [1, 22, 23]. A high frequency of chorioamnionitis has been observed but probably caused by associated ascending infections [22].

HIV has been demonstrated in villous trophoblast, endothelial, and stromal cells through immunohistochemistry or in situ hybridization even in placentas of very early gestation $[1,21,24]$.

By electron microscopy viral particles consistent with HIV have been observed within the syncytiotrophoblast, decidual cells, umbilical vessels, and less frequently within placental macrophages. These findings are associated with hyperplasia and hypertrophy of macrophages that contained increased number of lysosomes. However, the placentas of mothers submitted to antiretroviral treatment do not show viral particles or macrophage hyperplasia and hypertrophy [25]. Detection of the virus in the placenta can be achieved by immunohistochemistry using a p24-specific monoclonal antibody or by in situ hybridization [23, 24].

\section{HEPATITIS B}

The placentas of mothers with active hepatitis B may present a yellow-green discoloration of the villous tissue. Microscopically, large amounts of bilirubin are seen in the Hofbauer cells, the trophoblastic cells, and in the chorionic membrane macrophages but inflammatory infiltration and villous necrosis are not detected. Nevertheless, focal syncytial necrosis can be observed in placentas of women with hepatitis B [13]. In some studies in which the fetal infection was well proved, the placentas were not evaluated [26, 27]. Lucifora et al. studying placentas of asymptomatic carriers through immunohistochemistry, observed hepatitis B surface antigen ( $\mathrm{HBsAg}$ ) and hepatitis B core antigen ( $\mathrm{HBcAg}$ ) in Hofbauer cells, trophoblast, fibroblasts, and capillary villous endothelium [28, 29]. Morphologic 
examination of the placentas showed only prominent congestion of the villous capillaries and edema of the villous stroma. There are no placental studies in hepatitis A, C, E, and G [13].

\section{VARICELLA AND VACCINIA}

The placental lesions in varicella, smallpox, and vaccinia are similar in many features but the most severe lesions were found in smallpox. Smallpox has been successfully eradicated so that cases of smallpox infection should no longer be seen.

Besides the usual features of hematogenous placentitis, widespread miliary yellow-whitish areas, distributed in the villous plate and fetal surface, may be observed. The microscopic examination detects granulomatous villitis with extensive areas of necrosis (Figure 9) [30]. However, placental alterations in maternal varicella are not a frequent finding [31].

Nuclear inclusions can be seen in decidual cells [30]. In some cases no inclusions are observed in the placentas, but the diagnosis can be achieved through examination of fetal organs or by molecular biology [13].

Maternal vaccination during pregnancy also may cause severe fetal and placental lesions, identical to those described above [30].

\section{HERPES SIMPLEX}

In addition to the hematogenous route, the placenta and adnexae may become infected by the ascending route [32] or by contiguity with latent endometrial lesions [33].

The herpetic villitis is generally diffuse. It consists of lymphoplasmacytic infiltration and villous necrosis sometimes associated with a granulomatous reaction

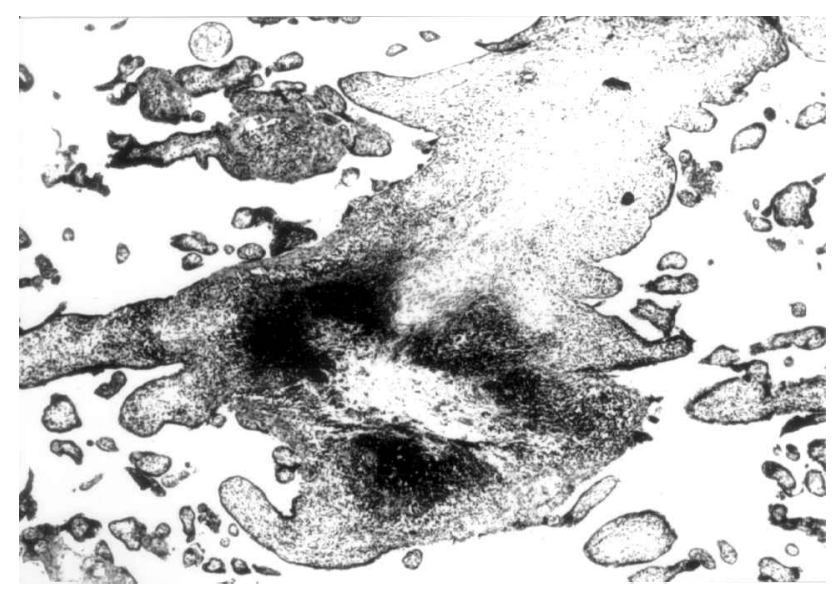

FIGURE 9. Placentitis of varicella. Note a stem villus with extensive necrosis and calcification $(\mathrm{H} \& \mathrm{E}, \times 40)$. 


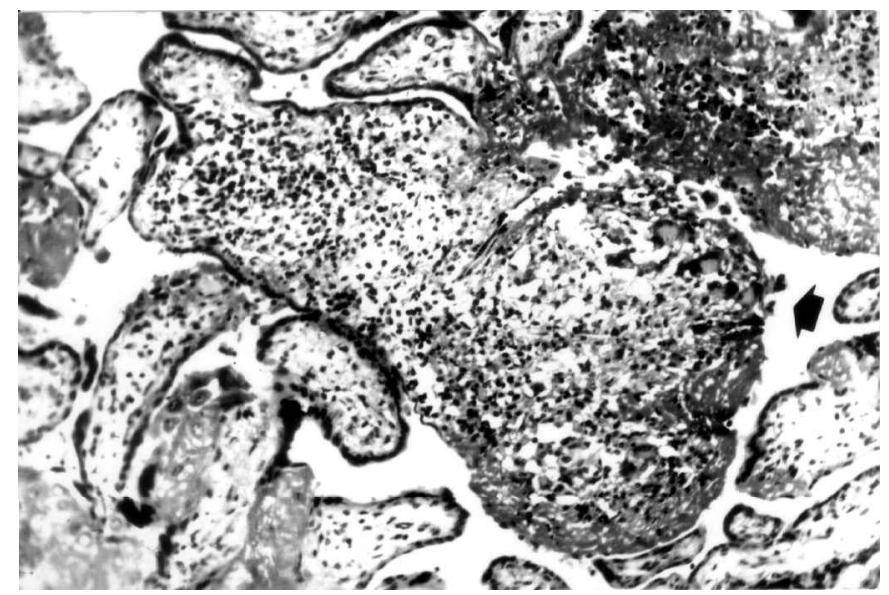

FIGURE 10. Herpetic placentitis. See necrotizing villitis and perivillitis and an area (arrow) with granulomatous reaction $(\mathrm{H} \& \mathrm{E}, \times 200)$.

(Figure 10). A similar infiltrate is observed in the decidua. Nuclear eosinophilic inclusions with nuclear margination of the chromatin has been observed in the amniotic epithelium, decidual cells, trophoblast, as well as in endothelial cells [34]. Infected cells can be detected in placenta and adnexae through immunohistochemistry, in situ hybridization, and/or electron microscopy even in placentas without inflammatory lesions $[35,36]$.

\section{PARVOVIROSIS}

Among 86 Brazilian cases of nonimmunologic fetal hydrops, Garcia et al. observed 6 cases of parvoviroses $(7 \%)$ [37]. The diagnosis was based on morphologic examination, in situ hybridization, dot-blot hybridization, and electron microscopy. Overall the placentas present increased weight and are pale and edematous. Hypotransparency of the membranes and thickening of the umbilical cord vessels are observed.

Intravascular nucleated red cells with nuclear inclusions can be seen by $\mathrm{H} \& \mathrm{E}$ staining (Figure 11). The most striking abnormality is vasculitis that affects all the placental vessels with swelling, fragmentation, or necrosis of endothelial cells. Besides hydrops and dysmaturity of the villous structures, chronic villitis and intervillitis are observed [37]. Villous necrosis with calcification also has been described [38]. In cases with transient hydrops, the placenta may be apparently normal, grossly and microscopically [39]. In some cases no inclusions are observed in the placenta but the diagnosis can be achieved by immunohistochemistry, using a commercially available monoclonal antibody, in situ DNA hybridization, or dot-blot hybridization [40-42]. These methods also must be used to confirm the histopathologic diagnosis. 


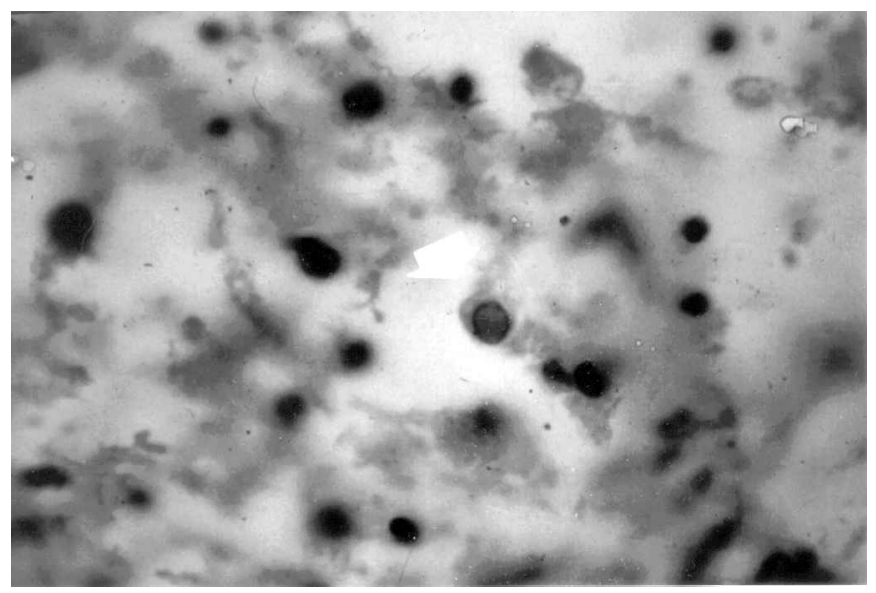

FIGURE 11. Parvovirosis. See an inclusion (arrow) in an erythrocyte $(\mathrm{H} \& \mathrm{E}, \times 1200)$.

\section{ENTEROVIROSES}

Placental lesions have been described in infections caused by echoviruses 11, 13, $15,17,18,19,21,23,24,25,27$, and 33, and coxsackie viruses A9, B2, and B6 [43-45]. They present the usual gross features of hematogenous placentitis, and the microscopic lesions are identical in both infections. The predominant patterns consist of acute villitis and intervillitis, intervillous thrombosis, extensive areas of necrosis, and vasculitis. Less frequently, chronic villitis with macrophagic predominance and a granulomatous pattern also can be seen (Figure 12). Chorionic and umbilical vessels exhibit areas of mural myolysis, edema, and scanty perivascular mononuclear infiltrate as well as invasion of the vessel wall by leucocytes. A heavy mono-

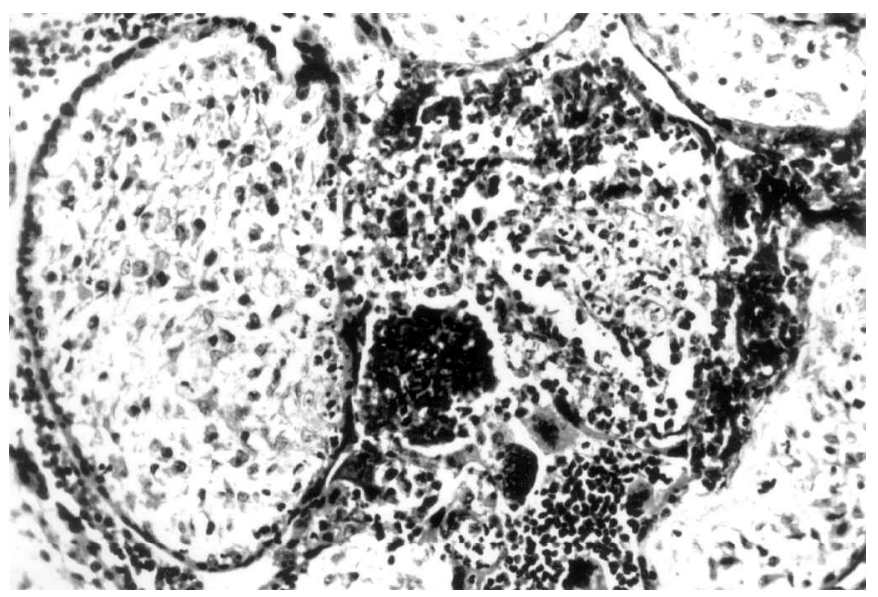

FIGURE 12. ECHO virus placentitis. Villus necrosis and a heavy infiltration of mononuclear cells. (H\&E, $\times 200)$. 
nuclear infiltration is a common finding in the stem vessels. In some cases, a mild mononuclear and neutrophilic infiltration is seen in the chorionic plate [43-45].

Although transplacental infection by poliovirus had been demonstrated through isolation of the virus from the placenta, there are no references to placental pathology [13].

\section{TOXOPLASMOSIS}

Congenital toxoplasma infections occur when the woman has her primary contact with Toxoplasma gondii during pregnancy. Notwithstanding, there are few reports of human toxoplasmosis occurring in successive pregnancies [46].

The parasite appears in the placenta as tachyzoites and/or cysts containing the bradyzoitic forms. The tachyzoites proliferate rapidly within vacuoles in their host cells and when the cytoplasm becomes full of parasites, the cell ruptures eliciting an inflammatory reaction [46].

When infection occurs during the first and second trimesters, the placenta exhibits more marked lesions [11]. Besides the gross features common to hematogenous placentitis, thrombosis and calcification of the chorionic and umbilical vessels may be observed [13].

The villous plate may exhibit arrest of maturation, vasculitis with necrosis and mineralization, and villous and perivillous mononuclear infiltration. Accumulation of mononuclear cells beneath the trophoblastic layer may be seen, sometimes associated with parasites. The inflammatory infiltration consists of macrophages, lymphocytes, and less frequently plasma cells. Granulomatous villitis is less commonly observed. Lymphoplasmacytic infiltration frequently is present in the decidua basalis and capsularis [11]. The parasite is predominantly seen in the cystic form in villous macrophages, capillary endothelium (Figure 13), and even within the trophoblast. The cysts also may be observed in Wharton jelly, in the chorion and amnion, and in the amniotic epithelium [11].

When the placental infection is recent, the parasites are more frequently detected and appear as tachyzoites. They are crescentic or oval in shape and measure 2 to $4 \mu \mathrm{m}$ wide and 4 to $8 \mu \mathrm{m}$ long. They may be observed in the villous plate and also in the amniochorium and Wharton jelly, sometimes within the amniotic epithelium [1].

Because of the similarity of $T$. gondii and the amastigote forms of Trypanosoma cruzi, it is necessary to make the differential diagnosis between these two organisms. Confirmation of diagnosis can be achieved through immunohistochemical methods.

\section{CHAGAS' DISEASE (AMERICAN TRYPANOSOMIASIS)}

The placental infection occurs when trypomastigotes present in the intervillous space penetrate the villous stroma where they transform into amastigotes 


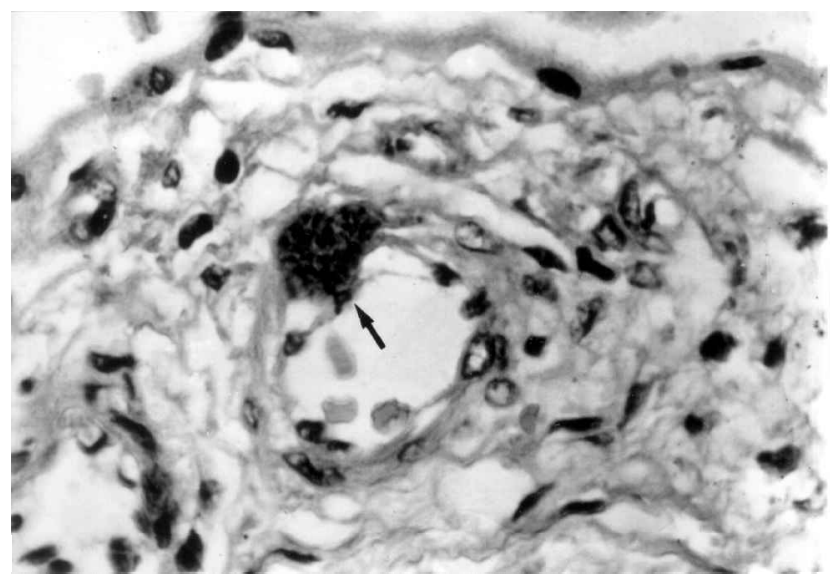

FIGURE 13. Toxoplasmosis. Chorionic villus. A toxoplasma cyst in seen (arrow) inside an endothelial cell $(\mathrm{H} \& \mathrm{E}, \times 200)$.

within macrophages (Figure 14). These forms proliferate until the affected cells rupture eliciting an inflammatory reaction.

In the subclinical neonatal infection, the placentitis is mild and focal without or with rare amastigotes. Sometimes the parasites are seen only in the umbilical cord. When associated with stillbirths and neonatal deaths, the placentas show a diffuse and marked villitis and perivillitis with heavy parasitism. The inflammation is usually chronic but it may also be subacute or chronic granulomatous with epithelioid and multinucleated giant cells. In the severe form of chagasic placentitis, there is extensive destruction of the villous trophoblastic epithelium, and diffuse infiltration of the stroma and surrounding intervillous space by macrophages,

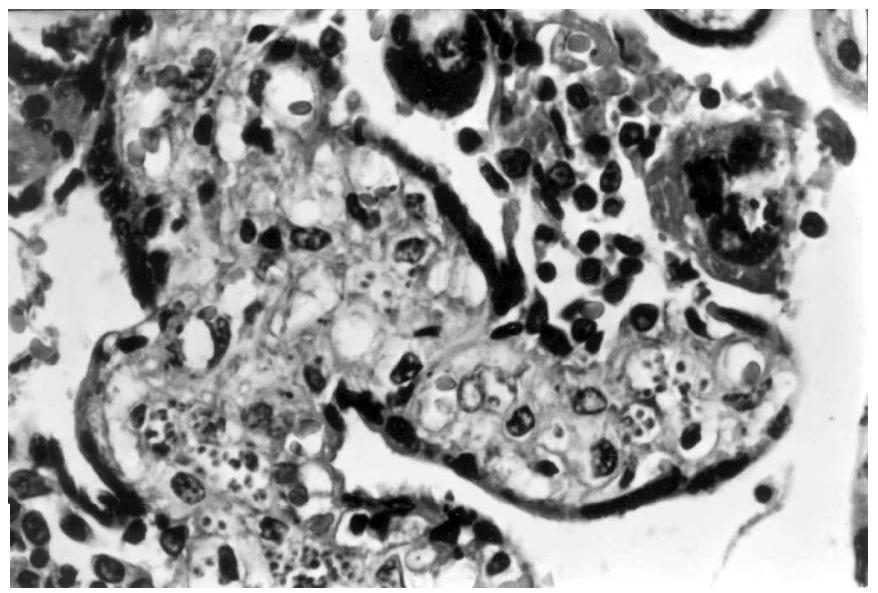

FIGURE 14. Chagasic placentitis. Villus macrophages have amastigotas forms of T. cruzi. An accumulation of mononuclear cells is seen in the neighborhood of trophoblast disruption $(\mathrm{H} \& \mathrm{E}, \times 200)$. 
lymphocytes, and less frequently by plasma cells and neutrophils. Complete disorganization of the villous plate frequently is observed resulting in villous aglutination and extensive necrosis. Separation of the trophoblastic epithelium from the villous stroma associated with the presence of mononuclear infiltration between these structures frequently is seen $[9,47]$.

A chronic subchorionic intervillitis and chorioamnionitis also have been observed. As in other congenital infections, placental involvement without fetal disease has been reported [9].

Immunocytochemical studies demonstrate that the inflammatory infiltrate in chagasic placentitis is composed mainly of CD68+ macrophages and CD8+ lymphocytes. MAC387+ monocytes of probable maternal origin and neutrophils $(\mathrm{CD} 15+)$ were observed attached to the areas of trophoblastic necrosis or below the intact trophoblast [48].

Parasites are usually present within macrophages in the villous plate, in the fetal surface of the placenta, and in vessels of the umbilical cord. However, in some cases, parasitized giant cells with single and large hyperchromatic nuclei have been observed. They are transformed macrophages and are probably related to the T. cruzi strain [49]. Amastigotes also have been observed inside the trophoblastic epithelium (Figure 15) [9].

Infection of the amnion of the free membranes has been described, associated with parasitism of the alveolar wall. The amniotic epithelium covering the umbilical cord may also be parasitized. The simultaneous observation of parasites in the amniotic epithelium and in the alveolar wall indicates that the amniotic fluid was infected in these cases [50]. In the umbilical cord, specific vasculitis and parasitism of Wharton jelly may be observed [47].

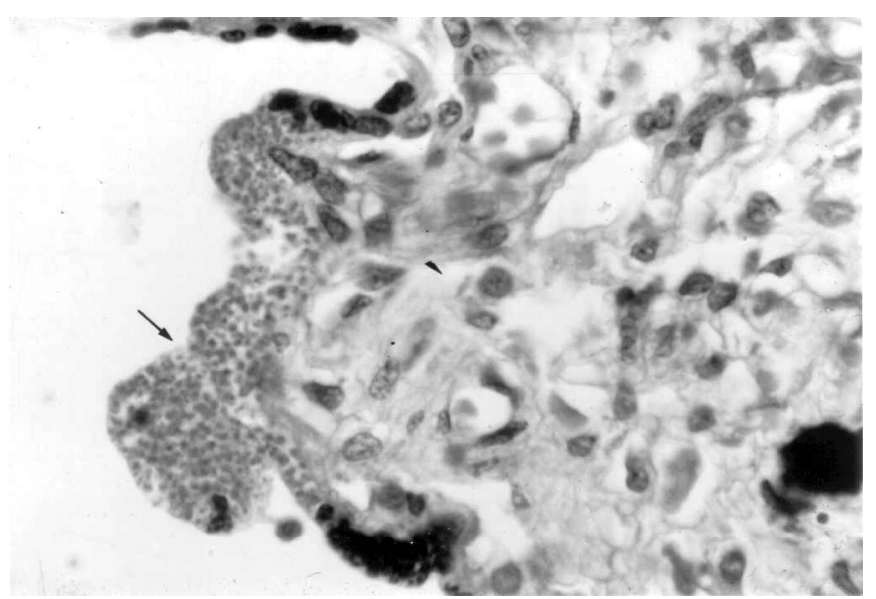

FIGURE 15. Chagas disease. Placenta of a 6-month-old-fetus. The trophoblast is full of amastigotas (arrow) $(\mathrm{H} \& \mathrm{E}, \times 1200)$. 
The amastigotes of T. cruzi may be histologically misdiagnosed as T. gondii. However, the amastigotes of $\mathcal{T}$. cruzi present anterior to the nucleus, the kinetoplast structure, that is lacking in toxoplasma [49]. Another means of differentiation is through staining by PAS method because only the toxoplasma cysts are PASpositive. In cases of doubt, immunohistochemical identification of amastigotes or toxoplasma using paraffin-embedded sections and anti-T.cruzi or antitoxoplasma antibodies are confirmatory. Considering that the placenta may be parasitized in visceral leishmaniasis [51], it is necessary to make the differential diagnosis between the amastigotes forms of T. cruzi and Leishmania donovani or L. chagasi achieved through immunohistochemical methods using monoclonal antibodies. Also, the different clinical aspects of maternal disease may enable the differential diagnosis.

\section{MALARIA}

Placental involvement in malaria is frequently observed even though congenital infection is a rare occurrence. Malarial-associated lesions has been observed in $52 \%$ and $56 \%$ of the placentas of endemic areas, but parasitism was observed in only $26 \%$ of them $[52,53]$. All species of plasmodium may cause placental changes that did not present qualitative differences $[53,54]$.

The macroscopic aspect of the infected placentas may be normal; however, its mean weight is significantly less than that of normal placentas. When severely affected, the organ may present a mottled gray discoloration on cut surface [54].

Placental malarial changes are represented by parasitism and cell concentration in the intervillous space, malarial pigment deposits, syncytiotrophoblast necrosis, and thickening of the trophoblastic basement membrane. Excess of perivillous fibrinoid deposits and syncytial knotting also are observed [54-56]. The placental changes are classified into three categories: (1) active infection when parasites in maternal erytrocytes and pigment in erythrocytes and/or monocytes are observed; (2) active chronic infection when, besides these aspects, pigment is found within fibrin, and in the villous stroma and/or villous syncytiotrophoblast; (3) postchronic infection when there is no parasitism and malaria pigment is observed within fibrin [52].

Intervillous inflammation is the most frequent pathologic finding associated with malaria and it is more severe in primiparas than in multiparas [57]. The cells present in the intervillous space are monocytes, macrophages and in less proportion $\mathrm{T}$ - and B-lymphocytes An increase in the number of monocytes, macrophages, and cytotoxic T-cells is associated with severity of infection [58]. The malarial intervillous infiltration must be differentiated from the massive chronic intervillositis, a placental lesion though to be of immunologic origin [8]. Focal villitis is found in some cases of malaria, but there is no evidence that it is caused by the plasmodium [56].

Parasites are seen within red blood cells (Figure 16) and/or macrophages in the intervillous space. All intraerythrocytic maturation phases of plasmodium are 


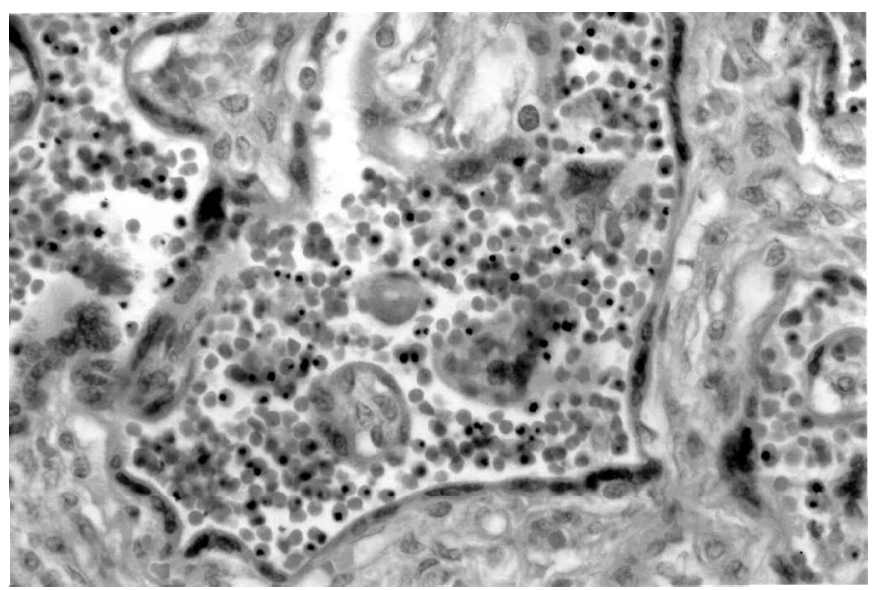

FIGURE 16. Malaria. Parasitized red blood cells are seen in the intervillous space (H\&E, $\times 1000)$.

observed in the intervillous space, but the trophozoitic forms predominate [54]. Researchers have demonstrated that placental histology is more sensitive than peripheral blood examination in detecting malarial infection during pregnancy [57]. Placental and umbilical cord blood parasitism are higher in HIV-positive mothers than in HIV-negative mothers [59].

Malarial brown pigment results from the destruction of parasitized red blood cells. It is seen in deposits of fibrinoid, within macrophages or free in the intervillous space, but less frequently it is also observed inside the trophoblast and villous stroma $[52,54]$. The histopathologic sections must be examined under polarized light to assess the presence of this pigment [52].

The perivillous fibrinoid deposits are generally associated with necrosis and other abnormalities of the trophoblast and its basement membrane. Ultrastructurally, partial microvillous loss, accumulation of a filamentous substance in the cytoplasmic vacuoles, and thickening of the basement membrane are observed [54, 56]. These lesions seem to have an immunologic basis. Depositions of plasmodium antigen, $\operatorname{IgG}$, and $\mathrm{C} 3$ have been detected in these structures [56].

The thickening of the trophoblastic membrane may alter fetomaternal exchange explaining the deleterious effect of placental lesions on fetal growth [53]. Excessive monocyte concentration present in the intervillous space in $28 \%$ of infected placentas and perivillous excess of fibrin might result in some decrease in perfusion and effective surface area for biochemical exchange [60].

\section{SYPHILIS}

The severity of placental syphilitic lesions depends on the age of gestation when infection occurs. Despite general knowledge that Treponema pallidum does not transmit before the 20th week of pregnancy, its presence has been well documented in 


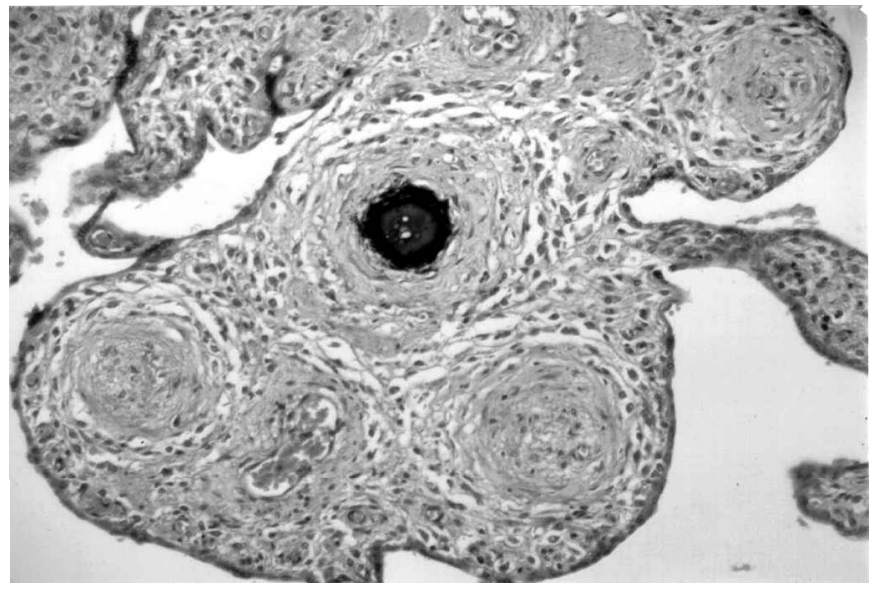

FIGURE 17. Syphilitic placentitis. Concentric fibrosis and proliferative endarteritis are observed in the vessels of the villus. One of the vessels presents central calcification. $(\mathrm{H} \& \mathrm{E}, \times 560)$.

9-10-week-old fetuses through electron microscopy and immunofluorescence techniques [13]. Braunstein [61] described typical placental lesions allied to the presence of T. pallidum in a 17-week-old abortion [61].

The placentas of stillbirths and neonatal deaths generally present the typical gross aspects of hematogenous placentitis. The umbilical cord is frequently involved and it may present milky and thickened vessels (Figure 3) [1].

The placental histologic aspects are characterized by villous hypercellularity, proliferative vascular lesions, and delay in maturation. The most severe proliferative vascular changes (Figure 17) consist of endovascular proliferations with narrowing of the lumen and perivascular concentric fibrosis [1, 62, 63]. V1llitis is represented by a lymphoplasmacytic infiltrate together with neutrophils. Intervillitis and the foci of necrotic villi surrounded by neutrophils are also observed. A granulomatous reaction may be observed, sometimes associated with gummas (Figure 18), although less frequently [64, 65]. Villitis and perivillitis may be absent in some cases of syphilitic placentas even when associated with perinatal deaths [64].

Lymphoplasmocytic infiltration with extensive areas of necrosis may be seen in the decidua. Acute subchorionic intervillositis, chorioamnionitis, and choriovasculitis also are observed [1].

The umbilical cord may show polimorphonuclear or mononuclear infiltration of the vessels and Wharton jelly. A necrotizing funisitis may be observed (Figure 19) that is considered highly suggestive of syphilis [66, 67]. However, it also can be observed in ascending infections [68, 69]. Studying 25 umbilical cords of women seropositive for syphilis, Schwartz et al. [70] observed that 50\% had normal histology, 39\% showed necrotizing funisitis, and only $11 \%$ had nonnecrotizing funisitis [70]. With only one exception, all the histologically normal-appearing cords 


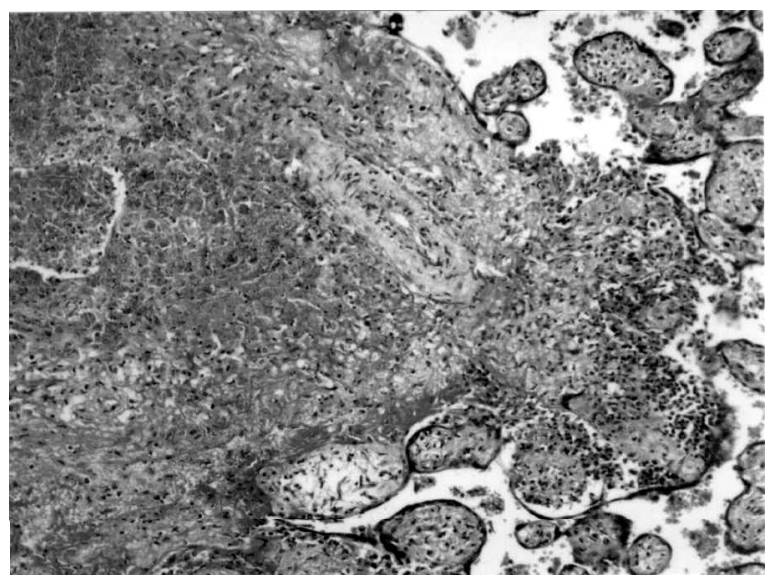

FIGURE 18. Syphilitic placentitis. There is an extensive area of gummatous necrosis. At right, note a granulomatous reaction involving some villi $(\mathrm{H} \& \mathrm{E}, \times 200)$.

presented spirochetes. They were observed in the vessels and in Wharton jelly, but they were more frequently seen in the vein wall.

Confirmation of syphilitic placentitis requires identification of T. pallidum in placental/fetal tissues. The organism may be visualized through silver impregnation (techniques of Levaditi, Steiner, or Warthin-Starry). It is more easily seen in the umbilical cord than in the placenta [1]. Spirochetes also may be detected in fresh imprints of the umbilical cord in dark field. Immunohistochemistry is useful to detect spirochetes in tissues $[65,67,70]$. According to Schwartz et al. the best methods for visualization of spirochetes are the modified Steiner procedure and the direct

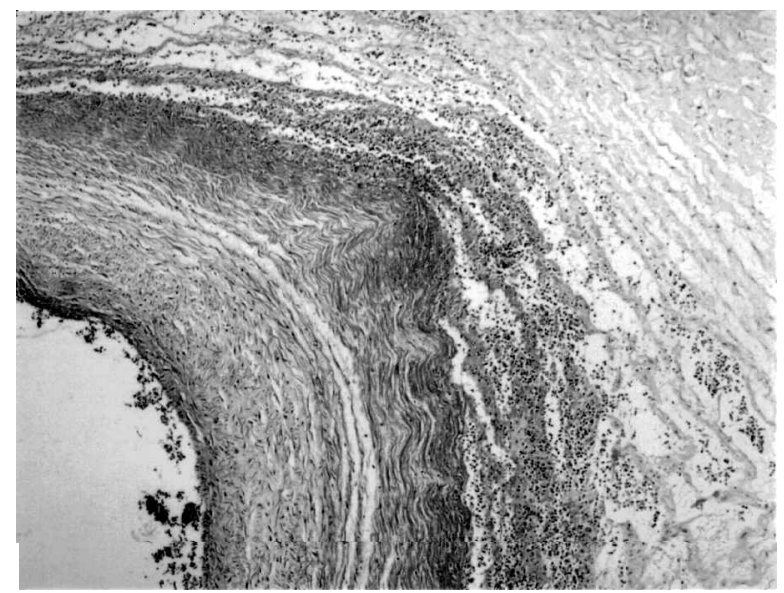

FIGURE 19. Syphilitic necrotizing funisitis. There are extensive necrosis of the Wharton jelly and the wall of the umbilical vein $(\mathrm{H} \& \mathrm{E}, \times 80)$. 
immunofluorescent test using antibodies anti-T.pallidum, both giving similar results $[70]$.

\section{LISTERIOSIS}

Placental infection by Listeria monocytogenes may occur through hematogenic and/or ascending routes. When there is an ascending and hematogenic infection, the placenta is enlarged, voluminous with a blurred outline, and the chorionic plate is covered by a thick yellow exudate commonly pinpointed by creamy, nodular, prominent areas. The presence of whitish and homogeneous areas in the maternal surface is more rarely observed. Small yellowish areas of necrosis are always seen in the villous plate (Figure 20). The presence of macroabscesses is the most characteristic finding of placental listeriosis [71].

Microscopic examination reveals an acute chorioamnionitis with subchorionic abscesses, necrosis of the chorionic vessels, and inflammation of the umbilical vessels associated with the presence of many Gram-positive bacilli. The involvement of the villous plate is expressed by abscesses of neutrophils (Figure 21). Older lesions are surrounded by granulomatous reaction with macrophages and epithelioid cells. The necrotic tissue is rich in organisms. The simultaneous presence of inflammation of the free placental membranes indicates that the infection had occurred both by the ascending and hematogenous routes. Silver impregnation is a good method for the identification of the bacilli in tissue sections, but the Brown-Hopps stain also can be used [1]. Comparing the histopathologic examination of placentas with the results of L. monocytogenes cultures, Topalowsky et al. concluded that listeriosis could be diagnosed by placental examination alone and that this examination enables the correct diagnosis even in cases not suspected clinically [71]. Other agents that less frequently cause intravillous abscesses are Campylobacter, Escherichia coli, Proteus

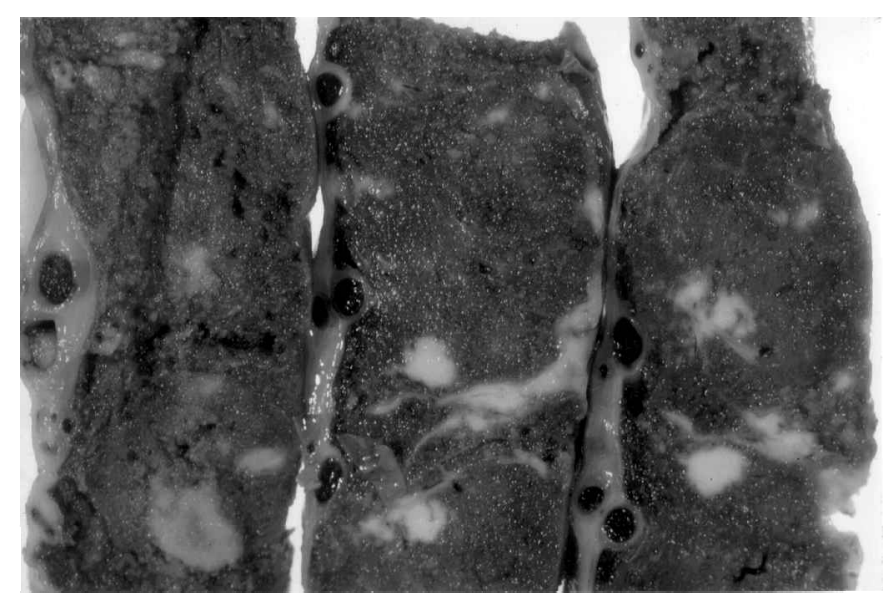

FIGURE 20. Placental abscesses caused by Listeria infection. 


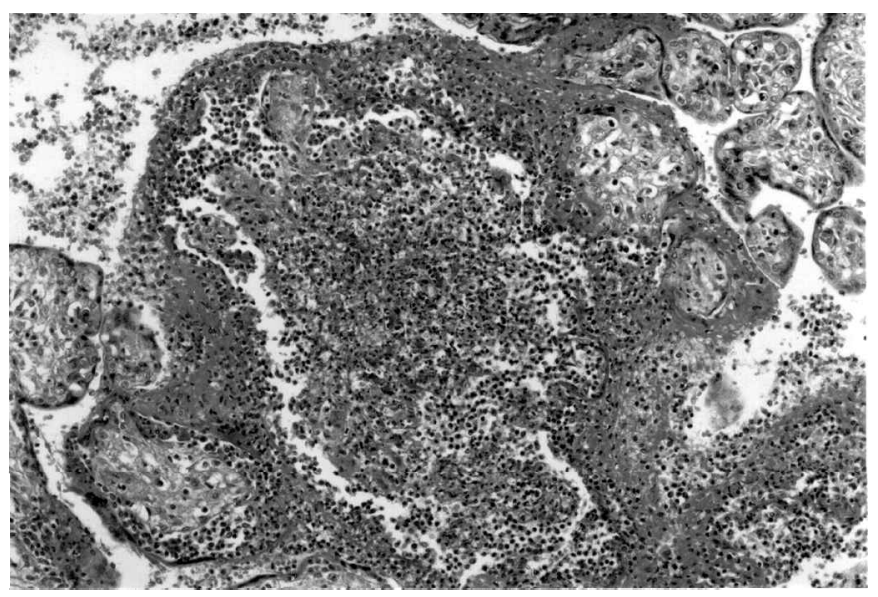

FIGURE 21. Histologic aspect of Figure 20. A wide abscess is surrounded by necrosis. At right, see a villus infiltrated with mononuclear cells $(\mathrm{H} \& \mathrm{E}, \times 200)$.

mirabilis, and staphylococcus. These agents can be differentiated from listeria by the Brown-Hopps method. However, care must be taken in the diagnosis since infection of Bacillus pumilis, a Gram-positive organism, may mimick listeriosis in the mother and causes acute villitis [72]. Immunohistochemical methods show an increase in sensitivity of detection of L. monocytogenes compared with routine bacterial stains [73].

\section{PLACENTAL INFECTIONS OF RARE OCCURRENCE}

\section{Mumps}

Severe and disseminated villous and intervillous mononuclear infiltration with extensive necrosis were observed in placentas of three abortions. The entire fetal vasculature was compromised in these cases. Eosinophilic and round inclusions were detected in the cytoplasm (Figure 22) of decidual cells and villous stromal cells [74].

\section{Measles}

In 2 term pregnancies in which the maternal infections occurred some days before delivery, vascular and villous lesions as well as intranuclear or intracytoplasmic, eosinophilic, round, or ovoid inclusions compatible with myxovirus were observed. Notwithstanding, the neonates were asymptomatic (Garcia, unpublished data). Moroi et al. identified the viral antigen by immunohistochemistry in decidua and syncyciotrophoblast in a case of fetal demise at 25 weeks, after an acute maternal infection [75]. The placenta was infiltrated by mononuclear cells but the fetus 


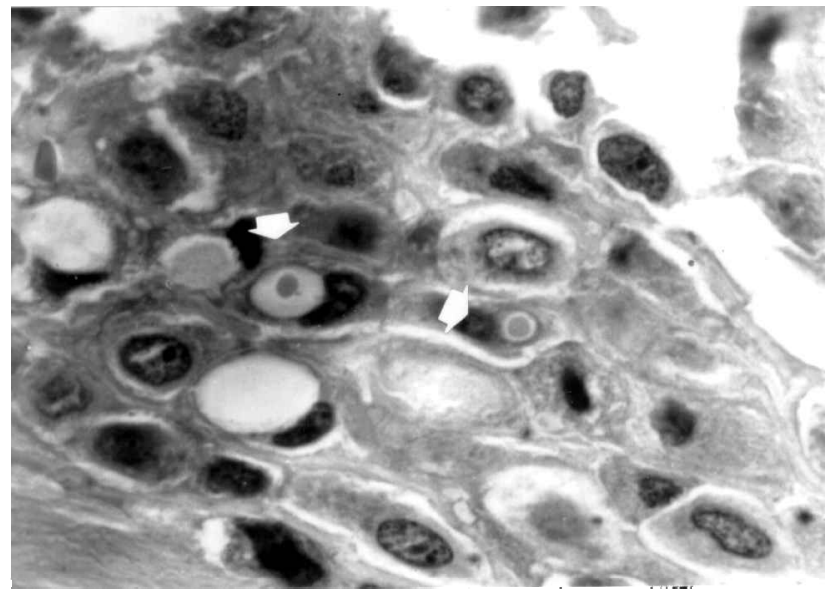

FIGURE 22. Mumps infection. Inclusions are seen (arrows) in the cytoplasm of decidual cells (H\&E, $\times 1200)$.

was not involved. There is no evidence in the literature of fetal involvement in measles [13].

\section{Human T-Cell Lymphotropic Virus Type One (HTLV-I) Infection}

Vertical transmission from HTLV-I carrier-mothers occurs mainly by breastfeeding, however, there are cases of vertical transmission in children who were not breastfed [76]. In these cases the infection may have occurred through the transplacental route or contamination in the birth canal. Other studies indicate that mother-to-fetus transmission may occur through the placenta. They demonstrated viral antigen or provirus in cord blood mononuclear cells $[77,78]$.

There is only one report of HTLV-I infection of the placenta. Fujino et al. studied cultured placental villous cells of nine placentas of HTLV-I-positive mothers using PGR and immunocytochemistry. They observed the presence of the virus in $22 \%$ of the placentas. Examination of the children was not performed. The manifestations of HTLV-I infection vertically acquired are of late-onset, generally occurring in adulthood.

\section{Schistosomiasis}

Placental schistosomiasis has been described in infection by Schistosoma mansoni and $S$. haematobium. In schistosomiasis by $S$. mansoni, the adult worms migrate against the blood flow from the portal system to the hemorrhoidal plexus. They deposit eggs in the vessels of the intestinal mucosa and submucosa, just as in the terminal branches of the mesenteric veins. Due to the existence of anastomoses between the hemorrhoidal plexus and the uterine veins, both worms and eggs can be carried along the female genital organs. Unlike the other pathogens that gain ac- 
cess to the placenta through the arterial circulation, the schistosoma and its eggs, localized in the uterine veins, attain the intervillous placental space through the venous circulation, moving against the bloodstream [80].

The rarity with which placental schistosomiasis is related may be due to the difficulty in finding eggs and the necessity of making many sections to obtain the diagnosis [81]. Renaud et al. dissolving 322 placentas with sodium hydroxide, found eggs of S. haematobium in $22.3 \%$ of their cases [81]. However, they obtained only $0.3 \%$ positivity by the study of routine histologic sections.

Gross placental abnormalities have not been observed in placental schistosomiasis. Microscopically, the lesions caused by S. mansoni predominate in the intervillous space but also can be seen in the decidua and in the villi. The eggs provoke a granulomatous reaction composed of macrophages, neutrophils, epithelioid cells (Figure 23), and less often multinucleated giant cells. In contrast to what is seen in other organs, eosinophils are not observed in the placenta. The granulomatous reaction present in the intervillous space may involve the neighboring villi with destruction of the trophoblastic epithelium. Eggs can be seen within the villi, either with or without an inflammatory reaction (Figure 23). The villitis and the presence of eggs inside the chorionic villus probably may result from trophoblastic lysis by enzymes liberated by the eggs. The lesions are mainly observed near the decidua. Less frequently, adult S. mansoni and schistosomules are seen inside decidual placental vessels or in the intervillous space. Foci of chronic inflammation or parasitized granulomas may be observed in the decidua [80].

The differential diagnosis of placental schistosomiasis should include other forms of granulomatous placentitis such as tuberculosis, Chagas' disease, toxoplasmosis, and some viral infections. When the lesions are localized in the neighborhood of the decidua, schistosomiasis is suggested, but a definitive diagnosis can only be made by identifying the parasite that requires study of many histologic sections.

\section{Visceral Leishmaniasis}

Placental involvement is rarely described in visceral leishmaniasis. The amastigotes are seen inside and outside villous macrophages in the absence of an inflammatory reaction. Focal necrosis of the trophoblast is also observed [51,82]. The tissue forms of the parasite are the amastigotes, that are structures identical to the amastigote forms of the T. cruzi.

\section{Borreliosis (Lyme Disease)}

Borrelia burgdorferi rarely affects the placenta. Placental changes range from unremarkable to inflammation of the villi with plasma cells and increased number of macrophages [83]. The organism has been detected even in placentas of asymptomatic infected mothers, although in a low frequency $(5 \%)$, as demonstrated 


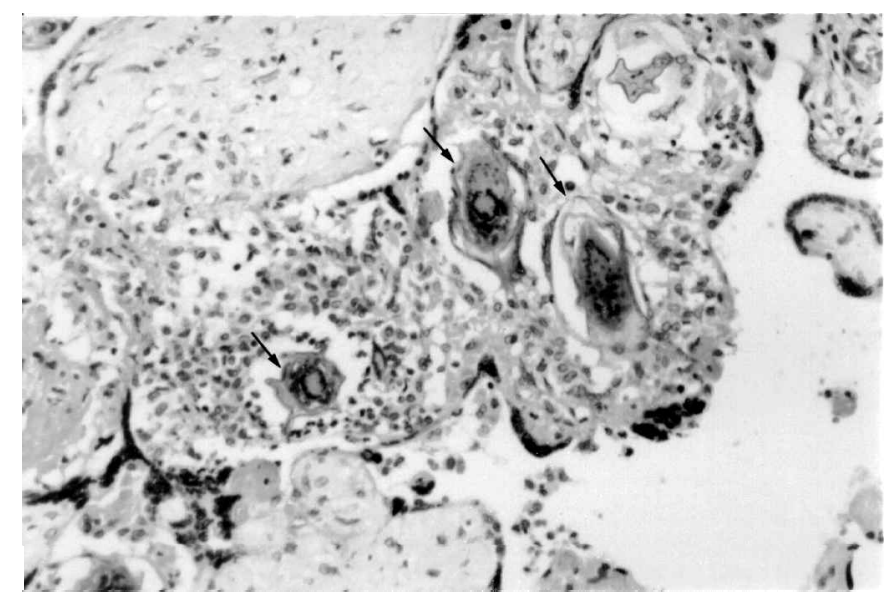

FIGURE 23. Schistosoma mansoni eggs (arrows) surrounded by a granulomatou s reaction are seen within a stem villus partially disrupted $(\mathrm{H} \& \mathrm{E}, \times 250)$.

through silver staining and confirmed by PCR [84]. Spirochetes can be visualized within villi, in the intervillous space or chorionic membranes through immunohistochemistry using monoclonal antibodies [83]. When spirochetes are detected in silver-stained preparations, it is mandatory to consider the differential diagnosis with syphilis.

\section{Brucellosis}

Brucellosis is a frequent cause of abortions in animals. Although this bacterium has been isolated from the human placenta and fetus, no inflammatory lesions have been described [13].

\section{Campylobacter Fetus}

There are rare reported cases of systemic C. fetus infection during gestation. When described, the placenta is abnormal, with necrosis or abscess formation. In some cases, the organism has been isolated from the placenta and fetal organs [85].

\section{Chlamydia}

The chlamydias are bacteria with an intracellular life and self-reproduction. Chlamidia trachomatis is pathogenic for humans and C. psittaci for animals. The placental $C$. trachomatis infection is considered to occur only by the ascending, route [13]. However, Garcia et al. described a placentitis by C. trachomatis that presented acute villitis and intervillitis associated with mild chorioamnionitis [86]. In this case chlamidial-like bodies were recognized in the villous trophoblast, extravillous cytotrophoblast, amnionic epithelium, and decidua in H\&E routine sections. 


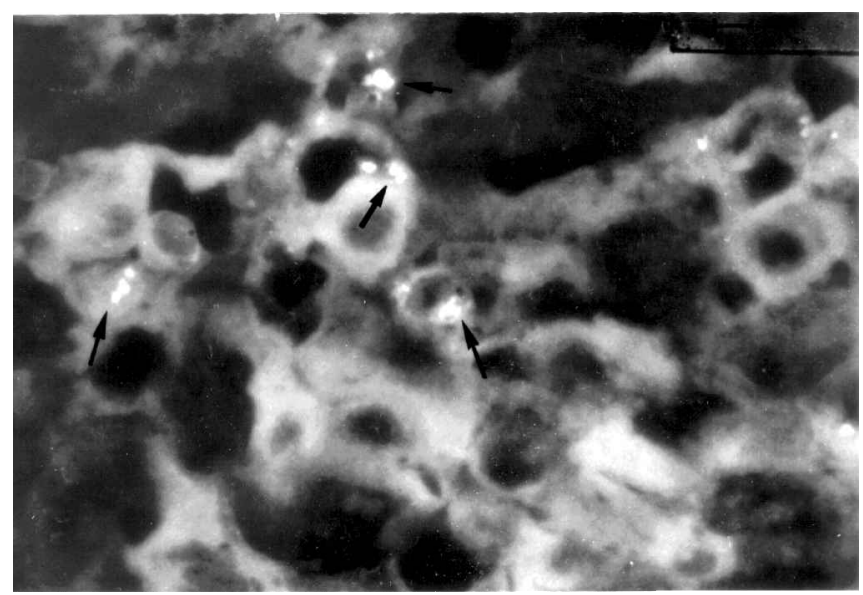

FIGURE 24. Chlamydia trachomatis infection. Chlamydial bodies (arrows) are seen in decidual cells by immunofluorescence using monoclonal antibodies anti-C. trachomatis (immunohistochemistry, $\times 1000$ ).

The indirect immunofluorescent test using antichlamidia monoclonal antibodies revealed apple-green intracellular structures with the same morphology (Figure 24) C. trachomatis was detected in the mother through routine cervical smears and was isolated from the cervix in cell culture.

The chlamydial bodies can be detected in $\mathrm{H} \& \mathrm{E}$ routine staining or in sections stained by Giemsa, PAS, and Papanicolaou. The diagnosis must be confirmed by isolation of chlamydia through culture, electron microscopy, or by immunohistochemistry using monoclonal antibodies anti-C. trachomatis [86, 87].

Placental C. psittaci infection is a frequent cause of abortion in sheep and other animals, although it is rarely recognized as a cause of human abortion and premature birth. In the reported human cases, the infection was of sheep origin acquired by farmers' women who assisted at sheep lambing [13, 87, 88]. Marked and acute intervillitis, villous necrosis, vasculitis, and large and dense basophilic intracytoplasmic inclusions have been described in grossly normal placentas. The inclusions are seen in the syncytiotrophoblast and cytotrophoblast on staining with H\&E, Giemsa, and methylene blue. They also can be stained specifically for chlamydial antigen using immunoperoxidase technique. By electron microscopy, inclusions are packed with chlamydial bodies [13, 87, 88].

\section{Leprosy}

Only women with the multibacillary forms of disease (lepromatous and borderline forms) may infect the placenta but it is very difficult to find Mycobacterium leprae in the placentas [13]. Duncan et al. examining 81 placentas of multibacillary patients did not detect bacilli in histologic lesions [89]. Detection of few acid-fast bacilli was possible in only 2 of 7 placentas studied through a concentration technique. 


\section{Q-Fever (Coxiella Burnetti Infection)}

Placental infection by C. burnetti has been rarely described. It consists of multiple foci of necrotizing villitis in which this organism can be identified by immunohistochemical staining $[90,91]$.

\section{Tuberculosis}

Placental infection may result from dissemination of Mycobacterium tuberculosis through the maternal blood to the intervillous space or by contiguity with tuberculous lesions of the oviduct and endometrium.

Placental involvement may be severe and extensive but in cases of early infection, bacilli can be found without microscopic lesions. Microscopically, granulomatous lesions with central caseous necrosis involving the decidua and the villi are observed [92]. These aspects must be differentiated from viral granulomatous lesions and schistosomiasis. In viral placentitis, other lesions are observed in addition to granulomas. Also, acid-fast bacilli are observed in tuberculous placentitis in sections stained by Ziehl-Nielsen or other similar methods.

\section{Tularemia}

It constitutes a rare congenital infection caused by Francisella tularensis. The placenta and the fetal organs present granulomatous lesions with central necrosis [13].

\section{Mycotic Infections}

There are references to hematogenous placental involvement in paracoccidioidomycosis, coccidioidomycosis, and cryptococcosis. However, the fungi are observed only in the intervillous space and the fetuses are not involved. Placental infection in paracoccidiomycosis is associated with severe forms of maternal disease [93, 94]. In the intervillous space, budding yeast forms of the Paracoccidioides braziliensis are detected associated with neutrophils.

The two cases of placental cryptococcosis (Cryptococcus neoformans infection) described in the literature occurred in immunodeficient women: one had AIDS and the other used immunosuppressive therapy for lupus erythematosus. Abundant cryptococcal yeast cells were observed in the intervillous space without inflammatory reaction [95, 96]. However, immunohistochemical labeling of villous stromal cells in one placenta showed an increased number of villous macrophages [95].

In cases of coccidioidomycosis, multiple infarcts have been detected. An acute inflammatory response with necrosis and fibrin deposition is observed, associated with spherules of Coccidioidis immitis [13].

The morphology of the fungi is better visualized with silver impregnation or PAS staining. The capsule of $C$. neoformans is strongly positive with mucicarmine or alcia-blue stains [96]. 
As is well known, placental candida infection occurs by an ascending route. However, two cases of placental candidiasis with acute villitis and perivillitis associated with ascending infection have been found [97,98]. In both cases the mothers had no systemic candidiasis. The villi were enlarged with necrosis and a heavy infiltration of neutrophils was seen in the intervillous space and in the adjacent villi. Hyphae were observed in the membranes and in the villous vessels and villous stroma. Here the infection of the villous plate was certainly acquired by a retrograde route from the fetal blood [98].

\section{REFERENCES}

1. Garcia AGP, Bittencourt AL. A placenta nas infecções hematogênicas. In Bittencourt AL. Infecções Congênitas Transplacentárias. Rio de Janeiro: Revinter, 1995;5-37.

2. Altschuler G, Russell P. The human placental villitides: a review of chronic intrauterine infection. Curr Top Pathol 1975;60:63-112.

3. Altshuler G. Pathology of the placenta. In Gilbert-Barness E. Potter's Pathology of Fetus and Infant. St. Louis: Mosby, 1997; 241-280.

4. Garcia AGP. Placental morphology of low-birth-weight infants born at term: gross and microscopic study of 50 cases. In Soma H. Morphological and Functional Aspects of Placental Development. Basel: Karger, 1982;100-112.

5. Greco MA, Wieczorek R, Sachdev R, et al. Phenotype of villous stromal cells in placentas with cytomegalovirus, syphilis, and nonespecific villitis. Am J Pathol 1992;141:835-842.

6. Redline RW, Patterson P. Villitis of unknown etiology is associated with major infiltration of fetal tissue by maternal inflammatory cells. Am J Pathol 1993;143: 473-479.

7. Altemani AM. Immunohistochemical study of the inflammatory infiltrate in villitis of unknown etiology. A quantitative and qualitative analysis. Pathol Res Pract 1992;188:303-309.

8. Jacques SM, Qureshi F. Chronic intervillositis of the placenta. Arch Pathol Lab Med 1993;117:1032-1035.

9. Bittencourt AL. American trypanosomiasis (Chagas' disease). In MacLeod C. Parasite Infections in Pregnancy and the Newborn. Oxford: Oxford University Press, 1988; 62-86.

10. Garcia AGP, Marques RLS, Lobato YY, et al. Placental pathology in congenital rubella. Placenta 1985;6:281-295.

11. Garcia AGP, Coutinho SG, Amendoeira RR. Placental morphology of newborns at risk for congenital toxoplasmosis. J Trop Pediatr 1983;29:95-103.

12. Garcia AGP, Marques RLS, Lobato YY. Placental morphology in cytomegalovirus infection. Placenta 1989;10:1-19.

13. Benirschke K, Kaufmann P. Pathology of the Human Placenta. New York: SpringerVerlag, 1995.

14. Drachenberg CB, Papadimitriou JC. Placental iron deposits: significance in normal and abnormal pregnancies. Hum Pathol 1994;25:379-385. 
15. Schwartz DA, Khan R, Stoll B. Characterization of the fetal inflammatory reponse to cytomegalovirus placentitis. An immunohistochemical study. Arch Pathol Lab Med 1992;116:21-27.

16. Moustofi-Zadeh M, Driscoll SG, Biano SA, et al. Placental evidence of cytomegalovirus infection of the fetus and neonate. Arch Pathol Lab Med 1984;108:403-406.

17. Sachdev R, Nuovo GJ, Kaplan G, et al. In situ hybridization analysis for cytomegalovirus in chronic villitis. Pediatr Pathol 1990;10:909-917.

18. Mühlemann K, Miller RK, Metlay L, et al. Cytomegalovirus infection of the human placenta: an immunocytochemical study. Hum Pathol 1992;23:1234-1237.

19. Sinzger C, Plachter B, Grefte A, et al. Tissue macrophages are infected by human cytomegaloviru in vivo. J Infect Dis 1996;173:240-245.

20. Ozono K, Mushiak ES, Takeshima T, et al. Diagnosis of congenital cytomegalovirus infection by examination of placenta: aplication of polymerase chain reaction and in situ hybridization. Pediatr Pathol Lab Med 1997;17:249-258.

21. Lewis SH, Reynolds-Kohler C, Fox HE, et al. HIV-1 in trophoblastic and villous Hofbauer cell and haematological precursors in eight-weeks fetuses. Lancet 1990;335:565-568.

22. Jauniaux E, Nessmannn C, Imbert MC, et al. Morphological aspects of the placenta in HIV pregnancies. Placenta 1998;9:633-642.

23. Backé E, Jimenez E, Unger M, et al. Vertical human immunodeficiency virus transmission: a study of placental pathology in relation to maternal risk factors. Am. J Perinatol 1994;11:326-330.

24. Martin AW, Brady K, Smith SI, et al. Immunohistochemical localization of HIV P24 antigen in placental tissue. Hum Pathol 1992;23:411-414.

25. Villegas-Castrejon H, Paredes-Vivas Y, Flores-Rivera E, et al. Comparative study of the placenta from HIV+ mothers. Ultrastructural analysis. Ginecol Obstet Mex 1996;64:167-176.

26. Li L, Sheng M, Tong SP, et al. Transplacental transmission of hepatitis B virus. Lancet 1986;2:872.

27. Mitsuda T, Yokota S, MoriT, et al. Demonstration of mother to infant transmission of hepatitis B virus by means of polymerase chain reaction. Lancet 1989;2:886- 888.

28. Lucifora G, Calabro S, Carrocio G, et al. HBsAg in placentas from Hepatitis B carrier mothers. AmJ Obstet Gynecol 1988;159:839-842.

29. Lucifora G, Martines F, Calabre S, et al. HBsAg identification in the placental cytotypes of symptom-free HBsAg-carrier mothers. A study with the immunoperoxidase assay. AmJ Obstet Gynecol 1990;163:235-239.

30. Garcia AGP. Fetal infection in chickenpox and alastrim with histopathological study of the placenta. Pediatrics 1963;32:895-901.

31. Quresh F, Jacques SM. Maternal varicella during pregnancy: correlation of maternal history and fetal outcome with placental histopathology. Hum Pathol 1996;27:191-195.

32. Hyde SR, Giacoia GP. Congenital herpes infection: placental and umbilical cord findings. Obstet Gynecol 1993;81:852-855.

33. RobbJA, Benirschke K, Mannino F, et al. Intrauterine latent herpes simplex viral infection. I. Spontaneous abortion. Hum Pathol 1986;17:1196-1209. 
34. Garcia AGP. Maternal herpes simplex infection causing abortion. Histopathologic study of the placenta. Hospital (Brazil) 1970;78:1267-1274.

35. Nakamura Y, Yamamoto S, Tanaka S, et al. Herpes simplex viral infection in human neonates: an immunohistochemical and electron microscopic study. Hum Pathol 1985;16:1091-1097.

36. Schwartz DA, Caldwell E. Herpes simplex viral infection of the placenta. The role of molecular pathology in the diagnosis of viral infection of placental-associated tissues. Arch Pathol Lab Med 1991;115:1141-1144.

37. Garcia AGP, Pegado CS, Cubel RCN, et al. Feto-placental pathology in human parvovirus B19 infection. Rev Inst Med Trop S Paulo 1998;40:145-150.

38. Samra JS, Obhrai MS, Constantine G. Parvovirus infection in pregnancy. Obstet Gynecol 1989;73:832-834.

39. Morey AL, Nicolino U, Welch CR, et al. Parvovirus B19 infection and transient fetal hydrops. Lancet 1991;337:496.

40. Rogers BB. Histopathologic variability of finding erythroid inclusions with intrauterine parvovirus $B_{19}$ infection. Pediatr Pathol 1992;12:883-889.

41. Essary LR, Vnencak-Jones CL, Manning SS, et al. Frequency of parvovirus B19 infection in nonimmune hydrops fetalis and utility of three diagnostic methods. Hum Pathol 1998;29:696- 701.

42. Cubel RGN, Garcia AGP, Pegado CS, et al. Human parvovirus B19 and hydrops fetalis in Rio de Janeiro, Brazil. Mem. Inst Oswaldo Cruz (Rio de Janeiro) 1996;91: 147-151.

43. Batcup G, Holt P, Hambling MH, et al. Placental and fetal pathology in Coxsackie virus A9 infection: a case report. Histopatholog y 1985;9:1227-1235.

44. Garcia AGP, Basso NGS, Fonseca MEF, et al. Congenital ECHO virus infectionmorphological and virological study of fetal and placental tissue. J Pathol 1990;160:123-127.

45. Garcia AGP, Basso NGS, Fonseca MEF, et al. Enterovirus associated placental morphology: a light, virological, electron-microscopic and immunohistologic study. Placenta 1991;12:533-547.

46. Remington JS, McLeod R, Desmonts G. Toxoplasmosis. In Remington JS, Klein JO. Infectious Diseases of the Fetus \& Newborn Infant. Philadelphia: WB Saunders, 1995;141-267.

47. Bittencourt AL. Congenital Chagas' disease. AmJ Dis Child 1976;130:97-103.

48. Altemani A, Bittencourt AL, Lana AM, Garcia AGP. Chagasic placentitis. Immunohistological study. AmJ Trop Med Hyg 2000;62:319-324.

49. Bittencourt AL, Ashworth T. American trypanosomiasis (Chagas' disease). In Doerr W, Seifert G. Tropical Pathology. Berlin: Springer Verlag, 1995;653-704.

50. Bittencourt AL, Freitas LA, Araujo MOG, et al. Pneumonitis in congenital Chagas' disease. A study of 10 cases. AmJ Trop Med Hyg 1981;30:38- 42.

51. Eltoum IA, Zulstra EE, Ali M, et al. Congenital Kala-azar and leishmaniasis in the placenta. AmJ Trop Med Hyg 1992;46:57-62.

52. Bulmer JN, Rascheed FN, Morrison L, et al. Placental malaria. II. A semi-quantitative investigation of the pathological features. Histopatholog y 1993;22:219-225.

53. Meuris S, Piko BB, Eerens P, et al. Gestational malaria: assessment of its consequences of fetal growth. AmJ Trop Med Hyg 1993;48:603-609. 
54. Walter P, Gavin JF, Blot P. Placental pathologic changes in malaria. Am J Pathol 1982;109:330-342.

55. McGregor IA, Wilson ME, Billewicz WZ. Malaria infection of the placenta in the Gambia, West Africa; its incidence and relationship to stillbirth, birthweight and placental weight. Roy Soc Trop Med Hyg 1983;77:232-244.

56. Yamada M, Steketee R, Abramowsky C, et al. Plasmodium falciparum associated placental pathology: a light and electron microscopic and immunohistologic study. Am J Trop Med Hyg 1989;41:161-168.

57. Ismail MR, OrdiJ, Menendez C, et al. Placental pathology in malaria: a histological, immunohistochemical, and quantitative study. Hum Pathol 2000;31:85-93.

58. OrdiJ, Ismail MR, Ventura PJ, et al. Massive chronic intevillositis of the placenta associated with malaria infection. Am J Surg Pathol 1998;22:1006-1011.

59. Steketee RW, Wirima JJ, Bloland PB, et al. Impairment of a pregnant woman's acquired ability to limit Plasmodium falciparum by infection with human immunodeficiency virus type-1. AmJ Trop Med Hyg 1996;55:42-49.

60. Galbraith RM, Faulk WP, Galbraith GM, et al. The human maternal-foetal relationship in malaria: I: Identification of pigment and parasites in the placenta. Trans Roy Soc Trop Med Hyg 1980;74:52-60.

61. Braustein H. Congenital syphilis in aborted second trimester fetus: diagnosis by histological study. J Clin Pathol 1978;31:265-267.

62. Quresh F, Jacques SM, Reyes MP. Placental histopathology in syphilis. Hum Pathol 1993;24:729-784.

63. Genest DR, Choi-Hong SR, Tate JE, et al. Diagnosis of congenital syphilis from placental examination: comparison of Histopathology, Steiner stain, and Polymerase Chain Reaction for Treponema pallidum DNA. Hum Pathol 1996;27:366-372.

64. Walter P, Blot P, Ivanoff B. The placental lesions in congenital syphilis. A study of six cases. Arch Pathol 1982;397:313-326.

65. Ohyama M, Itani Y, Tanaka Y, et al. Syphilitic placentitis: demonstration of Treponema pallidum by immunoperoxidase staining. Virchows Arch A Pathol Anat Histopathol 1990;417:343-345.

66. Fojaco RM, Hensley GT, Moskowitz L. Congenital syphilis and necrotizing funisitis. JAMA 1989;261:1788-1790.

67. Guarner J, Southwick K, Greer P, et al. Testing umbilical cords for funisitis due to Treponema pallidum infection, Bolivia. Emerg Infect Dis 2000;6:487-492.

68. Heifetz SA, Bauman, M. Necrotizing funisitis and herpes simplex infection of placental and decidual tissues: study of four cases. Hum Pathol 1994;25:715-722.

69. Wright-JrJR, Stinson D, Wade A, et al. Necrotizing funisitis associated with Actinomyces meyeri infection: a case report. Pediatr Pathol 1994;14:927-934.

70. Schwartz DA, Sandra A, Larsen SA, et al. Pathology of the umbilical cord in congenital syphilis: analysis of 25 specimens using histochemistry and immunofluorescent antibody to Treponema pallidum. Hum Pathol 1995;26:784-791.

71. Topalovsky M, Yang SS, Boonpasat Y. Listeriosis of the placenta: clinicopathologic study of seven cases. Am J Obstet Gynecol 1993;169:616-620.

72. Workowsky KA, FlahertyJP. Systemic bacillus species infection mimicking listeriosis of pregnancy. Clin Infect Dis 1992;14:694-696. 
73. Parkash V, Morotti RA, Joshi V, et al. Immunohistochemical detection of Listeria antigens in the placenta in perinatal listeriosis. Int J Gynecol Pathol 1998;17:343-350.

74. Garcia AGP, Pereira JMS, Vidigal N, et al. Intrauterine infection with mumps virus. Obstet Gynecol 1980;56:756-759.

75. Moroi K, Saito S, Kurata T, et al. Fetal death associated with measles virus infection of the placenta. Am J Obstet Gynecol 1991;164:1107-1108.

76. Hirata M, HayashiJ, Noguchi A, et al. The effects of breast-feeding and presence of antibody to $\mathrm{p} 40$ tax protein of human Tcell lymphotropic virus type-I on mother-tochild transmission. Int J Epidemiol 1992;21:989-994.

77. Saito S, Furuki K, Ando Y, et al. Identification of HTLV-I sequence in cord blood mononuclear cells of neonates born to HTLV-I antigen/antibody positive mothers by polimerase chain reaction. Jpn J Cancer Res 1990;81:890- 895.

78. Satow Y, Hashido M, Ishikawa K, et al. Detection of HTLV-I antigen in peripheral and cord blood lymphocytes from carrier mothers. Lancet 1991;338:915-916.

79. Fujino T, Fujiyoshi T, Yashiki S, et al. HTLV-I transmission from mother to fetus via placenta. Lancet 1992;340:1157.

80. Bittencourt AL, Almeida MAC, Yunes MAF, et al. Placental involvement in schistosomiasis mansoni. AmJ Trop Med Hyg 1980;29:571-575.

81. Renaud R, Brettes P, Castanier C, et al. Placental bilharziasis. Int J Gynecol Obstet 1972;10:24-30.

82. Silveira FT, Costa DP, Marques KC, et al. Leishmaniose visceral na gravidez: isolamento do L. chagasi da placenta humana. Rev Soc Bras Med Trop 1994;27:250.

83. Duray PH, Chandler FW. Lyme disease. In Connor DH, et al. Pathology of Infectious Disease. Stanford:Appleton \& Lange, 1997;635-646.

84. Figueroa R, Bracero LA, Aguero-Rosenfeld M, et al. Confirmation of Borrelia burgdorferi spirochetes by polymerase chain reaction in placentas of women with reactive serology for Lyme antibodies. Gynecol Obstet Invest 1996;41:240-243.

85. Gribble MJ, Salit IE, Isaac-Renton J, et al. Campylobacter infections in pregnancy. AmJ Obstet Gynecol 1981;140:423-426.

86. Garcia AGP, Leite MEL, Fonseca MEF, et al. Infecção materna por Chlamidia trachomatis associada a aborto fetal. J. Bras Ginecol 1994;104:383-386.

87. Wong SY, Gray ES, Buxton D, et al. Acute placentitis and spontaneous abortion caused by Chlamydia psittaci of sheep origin: a histological and ultrastructural study. J Clin Pathol 1985;38:707-711.

88. Johnson FWA, Matheson BA, Williams H, et al. Abortion due to infection with Chlamidia psittaci in a sheep farmer's wife. Br Med J 1985;290:592-594.

89. Duncan ME, Fox H, Harkness A, et al. The placenta in leprosy. Placenta 1984;5:189-198.

90. Friedland JS, Jeffrey I, Griffin GE, et al. Q fever and intrauterine death. Lancet 1994;343:288-289.

91. Raoult D, Stein A. Q-fever during pregnancy - a risk for women, fetuses, and obstetricians. N EnglJ Med 1994;330-371.

92. Kaplan G, Benirschke K, Tarzy B. Placental tuberculosis in early and late pregnancy. AmJ Obstet Gynecol 1980;137:858- 860.

93. Braga LF, Kasting G, Franke HJ. Placentite intervilosa paracoccidioidomicótica. Rev Bras Ginecol Obset 1989;6:117-120. 
94. Blota MHSL, Altemani AM, Amaral E, et al. Placental involvement in paracoccidioidomycosis. J Med Veter Mycol 1993;31:249- 257.

95. Kida M, Abramowsky CR, Santoscoy C. Cryptococcosis of the placenta in a woman with acquired immunodeficiency syndrome. Hum Pathol 1989;20:9 20-921.

96. Molnar-Nadasdy G, Haesly I, Reed J, et al. Placental cryptococcosis in a mother with systemic lupus erythematosus. Arch Pathol Lab Med 1994;118:757-759.

97. Rivasi F, Gasser B, Bagni A, et al. Placental candidiasis: report of four cases, one with villitis. Acta Pathol Microbiol Immunol Scand 1998;106:1165-1169.

98. Bittencourt AL, Santos WLC, Oliveira CH. Placental and fetal candidiasis. Mycopathologic a 1984;87:181-187.

99. Bittencourt AL, Garcia AGP. Anatomia Patológica das infecções congênitas. In Monteleone PPR, Valente CA. Infectologia em Ginecologia e Obstetrícia. São Paulo: Atheneu, 1998;310-334. 
Copyright of Pediatric Pathology \& Molecular Medicine is the property of Taylor \& Francis Ltd and its content may not be copied or emailed to multiple sites or posted to a listserv without the copyright holder's express written permission. However, users may print, download, or email articles for individual use. 